\title{
A comparison between the effects of sepiolite and silica on mechanical properties and thermal stability of NR/EPDM blend
}

\author{
Nattawat Winya ${ }^{1,2}$ and Nanthiya Hansupalak ${ }^{2}$ \\ ${ }^{1}$ Defence Technology Institute (Public Organization) Ministry of Defence, Nonthaburi Thailand \\ ${ }^{2}$ Department of Chemical Engineering, Kasetsart University, Bangkok, Thailand
}

\begin{abstract}
This study focused on improving the ablation properties and mechanical properties of natural rubber (NR)/ethylene propylene diene monomer (EPDM) blends by using two different commercial fillers: sepiolite and silica. The results showed that sepiolite and silica similarly improved both properties in the loading range of interest (0-12.5 phr). However, sepiolite was superior than silica as using less loading to acheive comparable mechanical and thermal properties. The optimum loading of sepiolite was $5 \mathrm{phr}$, while that of silica was $10 \mathrm{phr}$. For both filler systems, the minimum ablation rate found was approximately $0.17 \mathrm{~mm} / \mathrm{s}$, and the tensile strength and the hardness of corresponding NR/EPDM composite were improved after modification with sepiolite or silica. Thus, the composite reinforced with sepiolite or silica is suitable for many applications, such as internal insulations of rocket motor.
\end{abstract}

\section{Introduction}

The insulation for applications such as in rocket motor have very demanding requirement. Internal insulations in rocket motor protect structures from heat flux produces by the combustion of propellant in motor case. The combustions of propellant produces high velocity gases with temperature more than $2000^{\circ} \mathrm{C}$. The elastomers used for solid rocket motors (SRM), ethylene propylene diene monomer rubber (EPDM), nitrile butadiene rubber (NBR) and silicone rubber are used for the internal thermal insulation in solid rocket motor (SRM) [1, 2]. The development of novel materials on a commercial scale to fulfill these complicated requirements of high temperature internal insulations for rocket motor and development of further uses of natural rubber has been applied for the insulation of rocket motor. Although, fillers have been successfully that the addition of reinforcing fillers used to enhance the mechanical properties of the composites if properly added [3]. However, fillers are available in diverse range of properties such as specific gravity, color, electrical and thermal conductivities etc. therefore; desired properties of composite can be very easily varied by selecting proper filler. Silica is an amorphous material composed of silicon and oxygen atoms connected with silanol (Si-OH) both inside and on the surface. The silanols group that provide hydrophilic characteristics to silica surface and moisture readily on silica surface [4].

We would like to note that during the mixing process, the chemical reaction occurs between aggregates of silica and natural rubber chains. To avoid the complications, a silane coupling agent is needed to improve silica-rubber interaction and silica dispersion as well as to prevent accelerator adsorption on the silica surface [5-9]. Sepiolite is a hydrated magnesium silicate clay ( $\mathrm{Mg} 2 \mathrm{H} 2 \mathrm{SiO} 3 \mathrm{O} 9 . \mathrm{xH} 2 \mathrm{O})$, Sepiolite has a similar structure to the layered structure of montmorillonite except that the layers lack continuous octahedral sheet [10-11]. The acicular morphology of sepiolite generally improves adhesion/compatibility with polymeric matrices and provides an excellent reinforcing effect on polymer [12] and sepiolite improved the endothermic nature of decomposition reaction. This filler increased the tendency of the matrix to charring. Thus, the sepiolite can be selectd as promising materials for innovation of ablative materials [13]. The oservations confirmed the presence of Needles of sepiolite shown that Fig. 1.
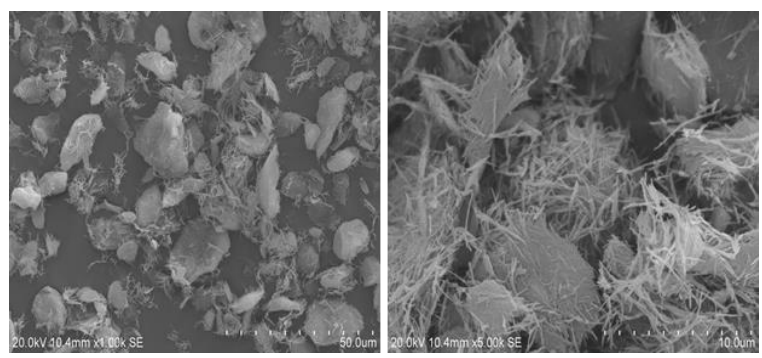

Figure 1. SEM micrographs of sepiolite powders.

Lombardi et al. focused on the thermal properties of poly(phenylene oxide)/polystyrene (PPO/PS) composites filled with modified clay, hydrotalcite and Sepiolite. The hydrotalcite added PPO composites shows that the degradation and combustion occurs at low temperatures and in a shorter time than the pure PPO polymer. While 
the modified clay added PPO composites and the Sepiolite added PPO composite were a higher thermal stability and a more endothermic decomposition, but the modified clay added PPO composites was brittle char layer during combustion. Thus, the Sepiolite added PPO composite can be selected as promising materials for innovative ablative shields [13]. Yue Guan et al. studied the ablative properties and ablation mechanisms of hydrogenated nitrile butadiene rubber (HNBR) composites filled with fumed silica (FS), organically modified montmorillonite (OMMT), and expanded graphite (EG).From studies HNBR composite as a result found that the ablative of HNBR/OMMT composites exhibits the best ablation resistance among three kinds of HNBR based composites [14]. Jovanović et al. studied the rheological, mechanical properties, thermal stability and morphology of acrylonitrile-butadiene/ethylenepropylene-diene (NBR/EPDM) rubber blend with carbon black (CB) filler ranging from 60 to $100 \mathrm{phr}$. The experimental results showed that the optimum cure time (tc90), tensile strength and hardness increase but scorch time (ts2) and cure rate index (CRI) decrease with an increase in the $\mathrm{CB}$ content in NBR/EPDM rubber blend composite because $\mathrm{CB}$ can be attributed to the crosslink density of rubber blend. The NBR/EPDM/CB (80/20/70) rubber blend has maximum tensile strength. However, the composite was degraded at a lower temperature, compared to the NBR and EPDM rubber. Furthermore, it was found that rubber and $\mathrm{CB}$ are compatible $[15,16]$. The objective of this work was to understand the effects of fillers loading on ablation and mechanical properties of natural rubber (NR)/ethylene propylene diene monomer (EPDM) blends. The influence of two types of filler (i.e.,sepiolite and silica) on the selective ablation and mechanical properties of NR/EPDM-filler composite.

\section{Materials \& methods}

\subsection{Materials}

NR (natural rubber, STR 5L), Silica (VN-3), Sepiolite (sigma-aldrich), Fiber (Aramid-pulp), Antioxidant (Winstay S), Flame retardant (Dechlorane Puls 515), Antimony Oxide, stearic acid, Silane, Sulphur and oil.

\subsection{Measurements}

The mechanical properties were measured by tensile TECH 91202 serial no.TBD-2730 according to JIS K6251.

The hardness (Shore D) was measured by Teclock GS-706N according to JIS K6268.

The density measured by METTLER TOLEDO (XS204) according to JIS K6268.

The curing times (t90) of the compounds were obtained by EKTRON at $170{ }^{\circ} \mathrm{C}$.

The compounds were subsequently compression molded by GOTECH (GT-7016) at $170{ }^{\circ} \mathrm{C}$, beased on the respective $\mathrm{t} 90$ values.

Ablation rate was measured using oxygen and acetylene ablation testing equipment according to ASTM
E285 (Fig. 2). The test specimen shall be a square five replicates and calculate the ablation rate to the following equation is ablation rate $=$ thickness/ablation time.

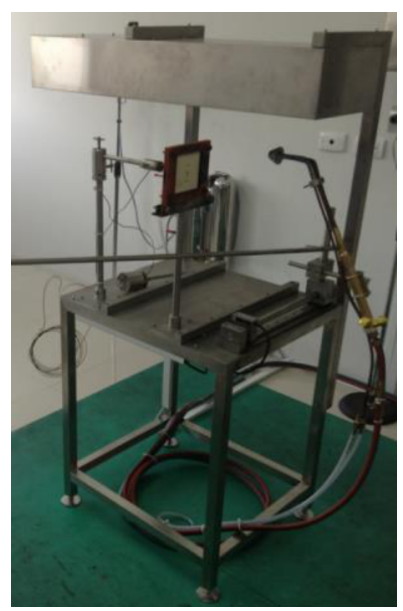

Figure 2. Test specimen of ablation test.

\subsection{Preparation of NR/EPDM composite}

Preparation of compound formulations are natural rubber was mixed at a temperature of $50{ }^{\circ} \mathrm{C}$. Non-vulcaized natural rubber composite containing antimony oxide, flame retardant, stearic acid, silica, sepiolite and silane coupling agents given in Table 1 . The composite rubber investigated contains $0,2.5,5,7.5,10$ and $12.5 \mathrm{phr}$ of type of filler varied, while all the other ingredients remained constant. After that will study curing characteristics, mechanical properties and ablation properties.

Table 1. Formulation for NR/EPDM composite

\begin{tabular}{|c|c|}
\hline Raw material and ingredients & $(\mathrm{phr})^{\mathrm{a}}$ \\
\hline NR & 80 \\
\hline EPDM & 20 \\
\hline Aramid-pulp & 20 \\
\hline Antioxidant & 2 \\
\hline Flame Retardant & 40 \\
\hline Antimony Oxide & 20 \\
\hline Silica/Sepiolite & $0,2.5,5,7.5,10,12.5$ \\
\hline Stearic acid & 1 \\
\hline Silane & 1 \\
\hline Co-agent & 2 \\
\hline DCP-40 & 5 \\
\hline
\end{tabular}

${ }^{\mathrm{a}} \mathrm{phr}$ stands for parts per hundred parts of rubber

\section{Results and discussion}

Table 2 shows that the curing characteristics of all rubber composilte with sepiolite and silica samples. The experimental results show that amount of sepiolite and silica have no significant effect on $\mathrm{M}_{\mathrm{L}}$ (minimum torque), 
$\mathrm{t}_{\mathrm{s} 2}$ (scorch time) and $\mathrm{t}_{90}$ (optimum cure time). The table also shows the curing characteristics of the hard rubber under investigation. Regular variations in the maximum torque $\left(\mathrm{M}_{\mathrm{H}}\right)$ and optimum curing time $\left(\mathrm{t}_{\mathrm{c} 90}\right)$ were observed for the reinforced blends. The NR/EPDM with $2.5 \mathrm{phr}$ of sepiolite demonstrated an optimal curing time. The initial decrease in torque.

Fig. 3 displays the maximum torque $\left(\mathrm{M}_{\mathrm{H}}\right)$ of all rubber composilte with sepiolite and silica samples. It was interesting to find out the maximum torque not much different when sepiolite and silica increased in rubber compound However, the maximum torque values of all the samples are increase of silica and sepiolite loading. The torque then increased due to the crosslinking between the molecular chains. Crosslinks are formed between the unsaturated sites and molecules during vulcanization. The maximum torque increases proportional to the indicating crosslinking density enhancement because of the reinforcement.

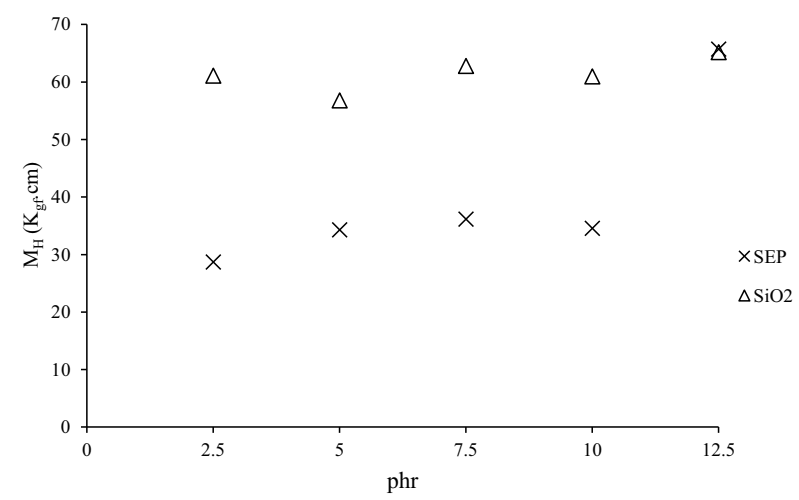

Figure 3. Maximum torque (MH) of hard rubber compounds

Table 2. Curing characteristics of NR/EPDM

\begin{tabular}{lccccc}
\hline & $\mathrm{ML}$ & $\mathrm{MH}$ & $\mathrm{T}_{\mathrm{s} 2}$ & $\mathrm{~T}_{\mathrm{c} 90}$ & $\mathrm{CRI}$ \\
\hline $0 \mathrm{SEP}$ & 51.04 & 25.89 & 0.42 & 5.19 & 21 \\
$2.5 \mathrm{SEP}$ & 55.64 & 28.71 & 0.42 & 5.21 & 20.9 \\
$5-\mathrm{SEP}$ & 60.73 & 34.3 & 0.42 & 5.11 & 21.3 \\
$7.5 \mathrm{SEP}$ & 63.09 & 36.14 & 0.42 & 5.04 & 21.6 \\
$10-\mathrm{SEP}$ & 63.23 & 34.53 & 0.42 & 4.45 & 24.8 \\
$12.5 \mathrm{SEP}$ & 35.9 & 65.7 & 0.42 & 4.54 & 24.3 \\
\hline $2.5 \mathrm{Si}$ & 33.01 & 61.11 & 0.03 & 5.17 & 19.5 \\
$5 \mathrm{Si}$ & 31.7 & 56.8 & 0.03 & 5.02 & 20 \\
$7.5 \mathrm{Si}$ & 33.24 & 62.79 & 0.03 & 5.1 & 19.7 \\
$10 \mathrm{Si}$ & 32.5 & 60.95 & 0.03 & 5.16 & 19.5 \\
$12.5 \mathrm{Si}$ & 35.78 & 65.18 & 0.03 & 5.05 & 19.9 \\
\hline
\end{tabular}

*the cure rate index $(\mathrm{CRI})=100 /\left(\mathrm{t}_{90}-\mathrm{t}_{2}\right)$

The effect of sepiolite and silica loading on tensile strength of NR/EPDM blends composite is shown in Fig. 4. Result showed that tensile of vulcanizates increased with the increase of sepiolite and silica loadings.
However, the effect was more significant when sepiolite and silica content was up to $7.5 \mathrm{phr}$ and then little decrease at $10 \mathrm{phr}$ for silica. At higher concentration, silica formed aggregates which had negative effect on mechanical properties of the vulcanizates.

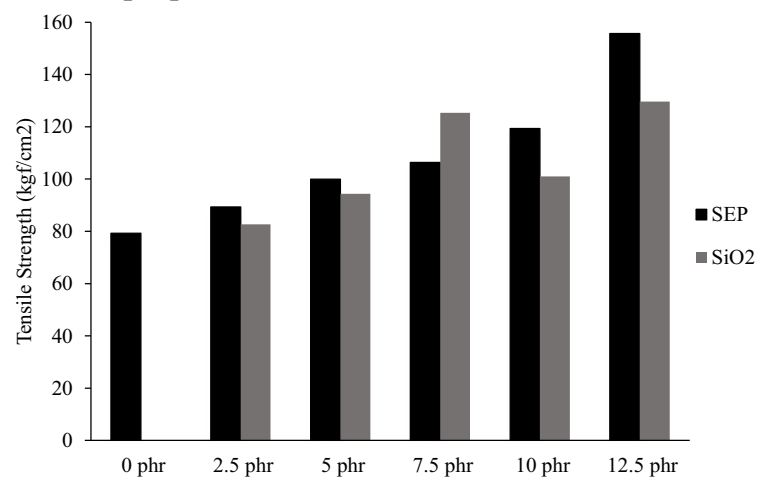

Figure 4. Tensile strength of NR/EPDM blends filled with sepiolite or silica

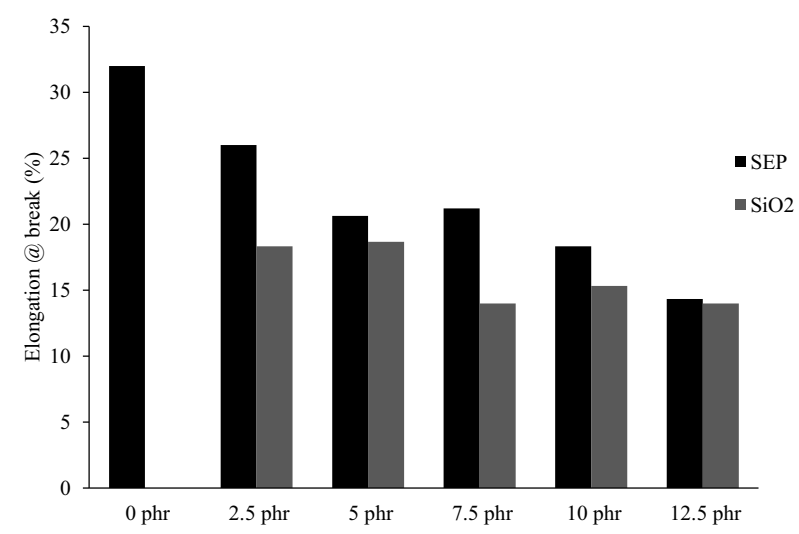

Figure 5. The elongation of NR/EPDM blends filled with sepiolite or silica

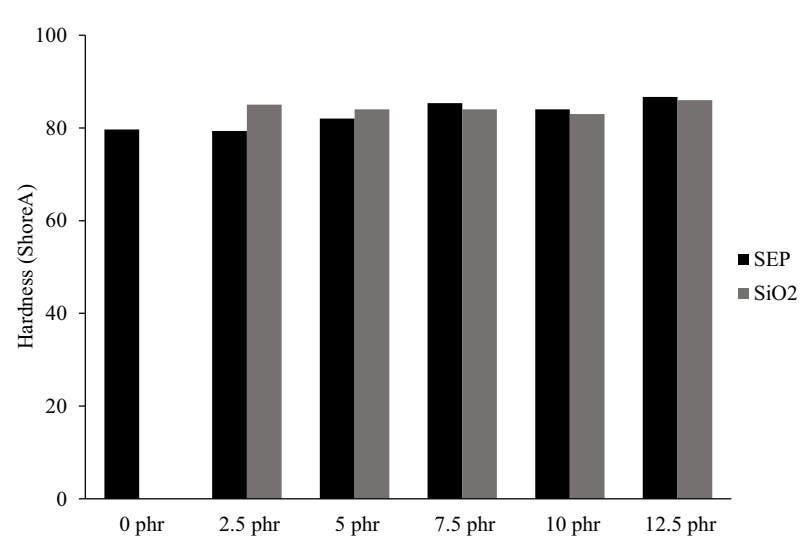

Figure 6. Hardness of NR/EPDM blends filled with sepiolite or silica

The effect of sepilolite and silica loading on elongation of NR/EPDM composite shown in Fig. 5. The result showed that elongation decreased with the increase of sepiolite and silica loading because of the reinforcement.

The Fig. 6. showed the effect of sepiolite and silica loading on hardness of NR/EPDM blends composite 
based vulcanizates. It clear from result that hardness of the vulcanizates increased with the increase of sepiolite and silica loading. In this study, the ablative properties of NR/EPDM blends filled with sepiolite and silica shown in Fig. 7. The experimental results showed that the ablation properties of NR/EPDM composite were improved after modification with sepiolite or silica. The effect of sepiolite loading on ablation rate composite decreased with increasing of sepiolite loading content in NR/EPDM composite. The NR/EPDM/SEP (80/20/5) rubber blend has minimum ablation rate. The NR/EPDM added $\mathrm{SiO} 2$ composites exhibits the best ablation resistance at $12.5 \mathrm{phr}$ of silica content in the NR/EPDM composite.

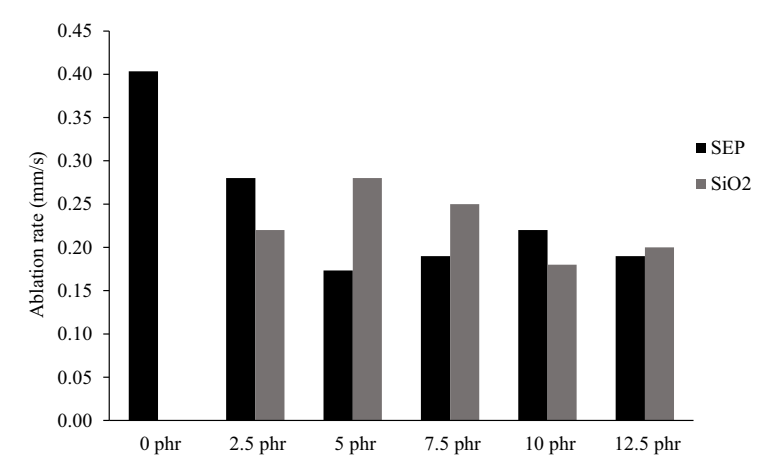

Figure 7. Ablation rate of NR/EPDM blends filled with sepiolite or silica

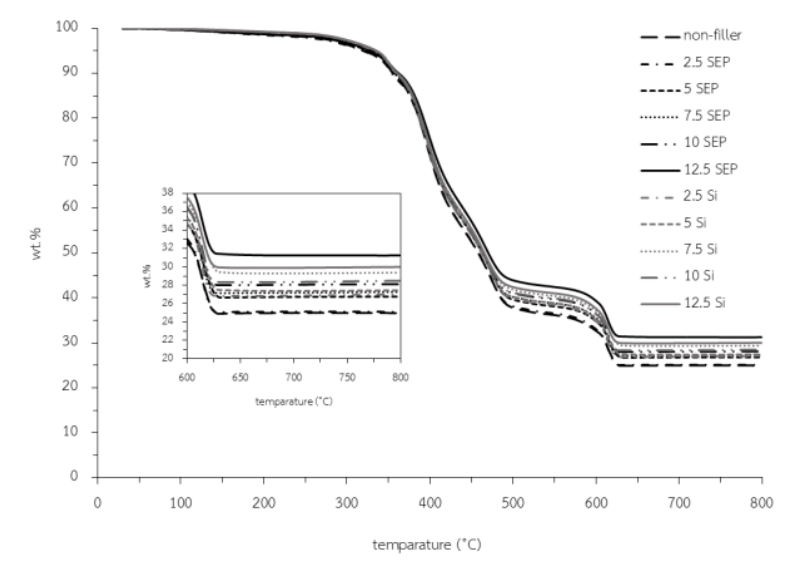

Figure 8. TG curves of NR/EPDM composites

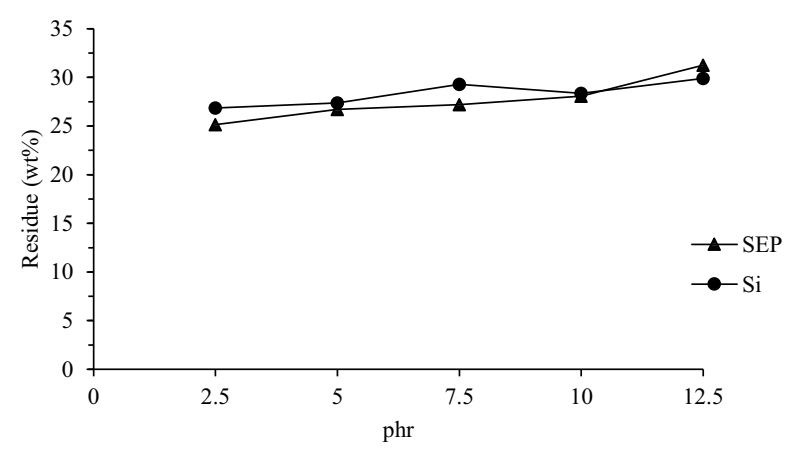

Figure 9. Experiment values of residues at $800{ }^{\circ} \mathrm{C}$ for NR/EPDM composite.
The TG thermos-gram of all NR/EPDM composites showed two thermal degradation transitions (Fig. 8.). The 1st transition at $360-450{ }^{\circ} \mathrm{C}$ of organic compounds with high molecular weight and second step, $600-635{ }^{\circ} \mathrm{C}$ and at $800{ }^{\circ} \mathrm{C}$, the char residue of NR/EPDM composite with $12.5 \mathrm{phr}$ of SEP was $31.3 \mathrm{wt} \%$ and NR/EPDM composite with $12.5 \mathrm{phr}$ of silica composite $29.9 \mathrm{wt} \%$ (Fig. 9). The sepiolite and silica did not change the degradation of NR/EPDM composites.

Morphological images of ablation test of composites shown in Fig. 10. Fig. 10c showed that char layer of NR/EPDM composites with sepiolite. It can see char layer formed on the surface of the $5 \mathrm{phr}$ of sepiolite was almost continuous and covered the surface. Fig. $10 \mathrm{~b}$ was surface after ablation test that displays the many sphere structures can be observed on the char layer surface should be made of silica. Sepiolite and silica to NR/EPDM composite enhance thermal ablation performance by forming char layer on the surface of composite.

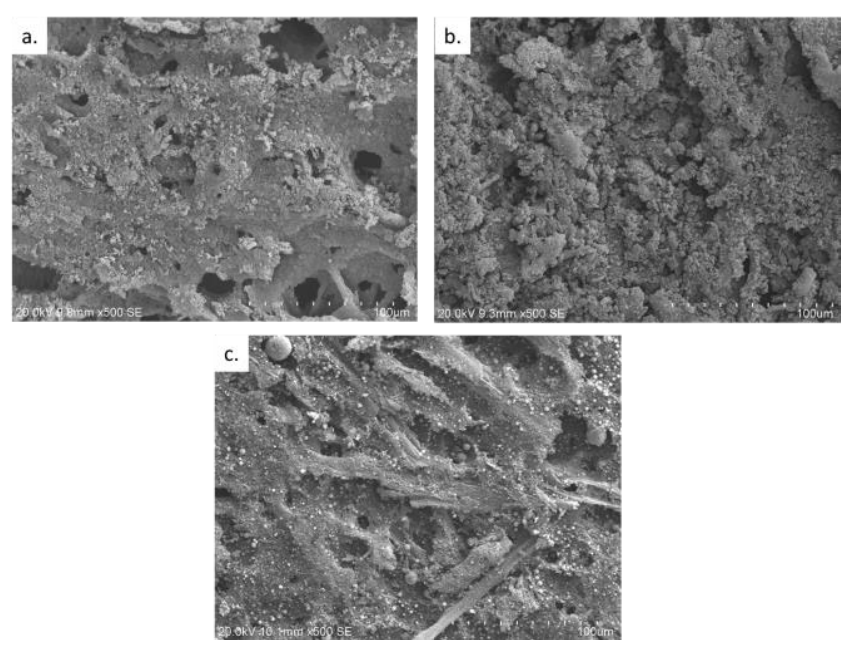

Figure 10. Images of morphology of surface after ablation test (a) NR/EPDM without fiilers, (b) NR/EPDM with $5 \mathrm{phr}$ of SEP and (c) NR/EPDM with $10 \mathrm{phr}$ of Silica

\section{Conclusion}

The effect of sepiolite and silica loading on tensile strength of NR/EPDM blends composite is showed that tensile of vulcanizates increased with the increase of sepiolite and silica loadings. However, the effect was more significant when sepiolite and silica content was up to $5 \mathrm{phr}$ and then little decrease at $10 \mathrm{phr}$ for silica. At higher concentration, silica formed aggregates which had negative effect on mechanical properties of the vulcanizates. The ablative properties of NR/EPDM blends filled with sepiolite and silica. The experimental results showed that the ablation properties of NR/EPDM composite were improved after modification with sepiolite or silica

\section{Acknowledgment}


This work was supported in part by Research and Development Department, The Defense Technology Institute (Public Organization), Nonthaburi, Thailand.

\section{References}

1. M.B Khan, Polymer Plast Tech Eng 36 (1996)

2. J.B Tan, World rubber industry(in chinese) 33, 6 (2006)

3. Q. Quifu Liu, Y. Zhang Xu, H., APPL CLAY SCI 42 (2008)

4. P. Sarawut and R. Nittaya, Polym Test 31, 5 (2012)

5. Z.Guozhang, S. Liyi, Z Dengsong, F. Xin, Y. Shuai and Z. Jing, Materials \& Design 35(2012)

6. S. Prasertsri andN. Rattanasom, Polym Test 30, 5 (2011)

7. T.H. Mokhothu, A.S. Luyt, M. Messori, Polym Test 33 (2014)

8. R.V.Sekharan, B.T.Abraham and E.T. Thachil, Materials \& Design, 40 (2014)
9. Y. Jiang, X. Zhang, J. HE, L.Yu and R. Yang, Polym Degrad Stabil, 96 (2011)

10. P. ArandaR, A. Kun, Martín-Luengo, S. Letaïef, I. Dekany and E. Ruiz-Hitzky, Chem. Mater. 20 (2008)

11. R. Benlikaya, M. Alkan and I. Kaya, Polym. Compos. 30(2009)

12. L. Bokobza, A. Burr, G. Garnaud, M.Y. Perrin and S. Pagnotta, Polym. Int. 53 (2004)

13. M. Lombardi, P. Fino, G. Malucelli, and L.Montanaro, Composite Structures, 94 (2012)

14. Y. Guan, Z. Ling-Xi, Z. Li-Qun, L.Yong-Lai, Polym Degrad Stabil. 96 (2011)

15. V. Jovanović, S. Samaržija-Jovanović, J. BudinskiSimendć, G. Marković, M. Marinović-Cincović,, Composites: Part B 45 (2013)

16. S. Samaržija-Jovanović, V. Jovanović, G. Marković, S. Konstantinović, M. Marinović-Cincović, Composites:Part B

42 (2011) 